\title{
Changes implemented for new manuscripts
}

\author{
Michel A. Aegerter ${ }^{1}$
}

Published online: 24 February 2018

(c) Springer Science+Business Media, LLC, part of Springer Nature 2018
With this editorial, we would like to inform JSST authors that many changes have been implemented recently for the submission of new manuscripts.

The first of these concerns the Highlights. This item is now mandatory and should consist of a collection of three to five bullet points, each one with a maximum of 100 characters. The bullet points should collectively convey the core findings of the article. Up to now the Highlights served purely editorial purposes and did not appear either in the online or printed issues of the journal. Upon further consideration, we have decided that they are important for all potential readers. The Highlights will therefore be incorporated below the keywords in all accepted articles (in both online and printed issues).

The submission of a Graphical Abstract (GA) is now also mandatory. It should be supplied at the time the manuscript is first submitted and, most importantly, accompanied by a detailed caption describing the GA. The $\mathrm{GA}$ is important as it helps readers to determine the content and importance of the manuscript at a glance. GAs should consist of carefully drawn figures (chemical structures, charts, graphs, or other informative illustration) that show the most striking feature of the article in a pictorial form. The figure(s) in the GA must meet the same quality and permissions standards as any other figure in the article. Compound numbers can be given in the GA if they refer to a graphic also shown there. The use of color to enhance the value and quality of the graphic is encouraged especially because each month the Editor-in-Chief selects one GA (recommended by the JSST editors) as the cover image for that month's issue of the journal; this is why GAs should ideally be approximately $123 \mathrm{~mm}$ in width and $90 \mathrm{~mm}$ in height. For each published paper, the GA and its caption now appear just below the Abstract and are followed by the

Michel A. Aegerter

michel.aegerter@bluewin.ch

1 Chemin des Placettes 6, 1041 Bottens, Switzerland
Keywords and the Highlights. Authors should bear in mind that, unfortunately, in the printed issue, the GA remains in black and white. At the end of the print issue Table of Contents are included the caption of the GA chosen for the cover, the title of the article in which it appears, the list of all authors with their addresses, and the page number of the article.

More information can be found on the JSST website under Instructions for Authors.

The last important information concerns the analysis of all submitted manuscripts for JSST against plagiarism, which has now been conducted on a routine basis by the JSST Editorial Manager peer-review system for several months using the iThenticate anti-plagiarism software. A report is first sent twice a week to the Editor-in-Chief; most of the 15 entries concerning each manuscript are common editorial information, but a few of them are of particular note for our ethical and quality checks, especially those informing about English language quality, Ethics compliance, and, most importantly, the percent match with previously published articles in scientific issues as well as on the internet. This first analysis is done with filters which exclude quotes, references, and sources that are less than 20 words. When the iThenticate percentage number and/or the percentage of a single source are too high, the JSST Journal Editorial Office Assistant is asked to send me the manuscript draft for a further detailed analysis in which all the copied and pasted sentences are highlighted in color with an indication of their sources (names of authors, title of the paper, and the name of the review from which these items are copied and pasted, or internet references, etc.). As I know that it is not easy to write an Introduction and an Experimental section without copying previously published papers, I usually add other filters that exclude matches which are less than eight to ten words. Such analysis is time-consuming and not easy to do, but it is necessary today. Presently, about $25-30 \%$ of the new submissions are rejected for plagiarism without being submitted for their scientific content. 